\title{
Implementing Mass Level Strategies Towards Prevention of Periodontal Disease
}

\author{
Bindiya K Pahuja $^{1 *}$ and Yasser Khaled ${ }^{2}$ \\ ${ }^{1}$ Department of Periodontology and Implantology, India \\ ${ }^{2}$ Department of General Dental Sciences, Marquette University, US
}

*Corresponding author: Bindiya K Pahuja, Department of Periodontology and Implantology, AIIMS, New Delhi, India

\begin{tabular}{|c|c|}
\hline ARTICLE INFO & ABSTRACT \\
\hline Received: 䍮 July 16, 2019 & Citation: Bindiya $\mathrm{K}$ Pahuja, Yasser Khaled. Implementing Mass Level Strategies \\
\hline Published: 幽 July 24, 2019 & $\begin{array}{l}\text { Towards Prevention of Periodontal Disease. Biomed J Sci \& Tech Res 20(1)-2019. BJSTR. } \\
\text { MS.ID.003386. }\end{array}$ \\
\hline
\end{tabular}

\section{Opinion}

\section{Why Periodontal Disease Prevention should be a Priority?}

Periodontal disease is a chronic inflammatory disease resulting in progressive loss of tooth supporting structures including alveolar bone [1]. It is so widely spread globally that it meets the criteria for consideration as a public health problem that requires action [2]. The population belonging to lower socio-economic group are most often affected, as are older individuals[3].It affects more than $50 \%$ of the adult population, while its severe forms affects $11 \%$ of adults who suffer consequences such as tooth loss, making severe periodontitis the sixth most prevalent disease of mankind[4]. While on the other hand periodontal disease is both preventable and treatable. Therefore, it is necessary to foster prevention, early management and cure of the disease.

\section{The Future Consequences of the Disease and Impact on General Health}

Local consequences include bleeding gums, swollen gums, bad breath, and formation of abscess, gum recessions, and gap between teeth, tooth mobility and subsequent tooth loss [5]. Which in term affects chewing habits and nutrition intake and impairs esthetics [6]. Further impacts on systemic health may include an increased level of systemic inflammation. There are various shared risk factors with cardiovascular (heart) disease, lung diseases, preterm low birth weight babies and diabetes [7].
The Potential Barriers in Implication of Mass Level Prevention Policies for Periodontal Diseases

a) Although oral health is recognized as an integral component of the right to health, it is still largely absent from governmental and intergovernmental health agendas.

b) In particular, public awareness of periodontal health remains low [8].

c) Periodontal disease is still too often considered as a purely 'cosmetic' problem rather than a medical condition.

d) Like any other chronic disease periodontitis is painless and doesn't provoke much attention form the patient [9].

e) The perception about the importance of oral health is different for different age groups. No single oral hygiene promotion program is applicable to people of all age groups [10].

f) The screening of community based periodontal disease requires an invasive and very tedious technique to measure the periodontal index of each patient.

g) The tailored oral health education programs demand a group of highly skilled, trained professional who have through knowledge of patient's cognitive behavior. 
h) Socio-economic barriers, lack of oral healthcare facilities within the reach of patient further complicates the patient's compliance.

i) Unadapt remuneration Tooth extraction and the placement of a dental implant are often more profitable to the dentist than the treatment of periodontitis per se, hence encouraging a purely curative rather than a preventive approach to periodontal disease.

Although there are so many potential barriers in disease assessment at mass level but because of its highly preventable nature a rapid improvement could be achieved through an "easy to implement" and "cost effective" measures, yielding a strong return on investment. The patients perceived benefits are tangible which in tern may effect the patients overall well-being and quality of life. This is why periodontal diseases need to be given visibility and priority.

\section{The Possible Solutions to Overcome the Above-Men- tioned Barriers}

a) Implementation of alternative screening methods for periodontitis which are less cumbersome and noninvasive. For example, using salivary markers as an indicator of periodontal disease [11]

b) Designing specific kind of health promotion programs for different age groups. For example, a preschool hygiene program would be different from hygiene program for adults and elderly and for the community [10].

c) Application of high yield effective motivational strategies, which can successfully modify behavior change. For example, a motivational interview will be more effective than a simple representation of their illness. The model is called selfregulation theory given by Leventhal and Cameron in 1987 has proven effective in bringing positive attitude change in population [12]

d) Implementation of a tailored motivational approach for each patient based on their cognitive behavior and SelfDetermination is the key to bring out desirable behavior change among population $[13,14]$.

e) The most important area is spreading the awareness about the disease not only among public but also among the health professionals. Currently, most health systems consider dentistry and medicine as two worlds apart, which tends to jeopardize effective collaboration and communication between oral health and medical professionals [9].

f) The government should promote dental insurance policies to cover people from lower economic strata who cannot otherwise afford oral health treatments. So far, the current feefor-service model fail to encourage a preventive approach to periodontal health. g) Implementing collaborating programs and partnerships. Collaborating with other to ensure an optimum use of resources can help efficient outcomes of results. For example, involving dental hygienists, dietitians and people involved in smoking cessation program into one team.

h) The visualization of oral biofilms is difficult for the patient. Use of three-dimensional educational models, use of plaque disclosing agents and magnifying mirrors will prove to be more effective aid than showing them posters.

i) Indulging public in Periodic periodontal maintainace where they may receive positive reinforcements in the form of small rewards such as a toothbrush or an interdental brush would be fruitful.

\section{Reaching the target population}

There are various ways to spread the message to the target population. This can be done through organizing an event or a workshop or via use of media. Mass media campaign, e.g. newspapers, radio and TV will allow you to reach a large audience, which can help generate momentum for your issue. However, this method is not appropriate for reaching decision makers. Now a day's Social media is a very powerful tool Consider that the use of social media has a very low set-up cost and offers new opportunities to engage with your target audiences. Printed materials, e.g. booklets, leaflets and factsheets, are very valuable in supporting your advocacy activities. It is useful to distribute them when you organize a meeting or activity [15].

\section{Summary}

The challenge for oral hygiene promotion is effective delivery of the message combined with effectual motivation of the individual with a personalized approach. The dream of periodontitis free world can be realized and materialized in near future with meticulous implication of health promotion policies. The dream cannot be fulfilled without the support from government and intragovernment agencies.

\section{Acknowledgement}

None.

\section{Conflict of Interest}

No conflict of interest.

\section{References}

1. Petersen PE, Ogawa H (2012) The global burden of periodontal disease: towards integration with chronic disease prevention and control. Periodontol 2000 60(1): 15-39.

2. Thomson WM, Sheiham A, Spencer AJ (2012) Sociobehavioral aspects of periodontal disease. Periodontol 2000 60(1): 54-63.

3. Borrell LN, Kunzel C, Lamster I, Lalla E (2007) Diabetes in the dental o ce: using NHANES III to estimate the probability of undiagnosed disease. J Periodontal Res 42(6): 559-565.

4. Tonetti MS, Chapple IL, Jepsen S, Sanz M (2015) Primary and secondary prevention of periodontal and peri-implant diseases: introduction 
to, and objectives of the 11th European workshop on periodontology consensus conference. J Clin Periodontol 42 Suppl 16: S1-4.

5. De Geest S, Laleman I, Teughels W, Dekeyser C, Quirynen M (2016) Periodontal diseases as a source of halitosis: a review of the evidence and treatment approaches for dentists and dental hygienists. Periodontol $20007(11): 213-227$.

6. Buset SL, Walter C, Friedmann A, Weiger R, Borgnakke WS, et al. (2016) Are periodontal diseases really silent? A systematic review of their e ect on quality of life. J Clin Periodontol 43(4): 333-344.

7. (2000) Periodontal Medicine: A New Paradigm.

8. Luo H, Wu B (2017) Self-awareness of 'Gum Disease' Among US Adults. J Public Health Manag Pract JPHMP 23(2): e1-e7.

9. (2018) Periodontal Health and Disease, A practical guide to reduce the global burden of periodontal disease, FDI world dental federation, Geneva, Switzerland.

10. Choo A, Delac DM, Messer LB (2001) Oral Hygiene Measures and Promotion: Review and Considerations. Aust Dent J 46(3): 166-173.

ISSN: 2574-1241

DOI: 10.26717/BJSTR.2019.20.003386

Bindiya K Pahuja. Biomed J Sci \& Tech Res

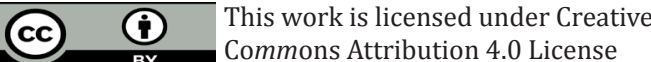

Submission Link: https://biomedres.us/submit-manuscript.php
11. Nomura Y, Okada A, Kakuta E, Gunji T, Kajiura S, et al. (2016) A new screening method for periodontitis: an alternative to the community periodontal index. BMC Oral Health 64 .

12. Godard A, Dufour T, Jeanne S (2011) Application of self-regulation theory and motivational interview for improving oral hygiene: a randomized controlled trial. J Clin Periodontol 38(12): 1099-1105.

13. Ryan RM, Patrick H, Deci EL, Williams GC (2008) Facilitating health behaviour change and its maintenance: Interventions based on SelfDetermination Theory 10.

14. Jönsson B, Öhrn K, Oscarson N, Lindberg P (2009) The effectiveness of an individually tailored oral health educational programme on oral hygiene behaviour in patients with periodontal disease: a blinded randomizedcontrolled clinical trial (one-year follow-up): Individually tailored oral hygiene treatment. J Clin Periodontol 36(12): 1025-1034.

15. Flora JA, Maibach EW, Maccoby N (1989) The Role of Media Across Four Levels of Health Promotion Intervention 10: 181-201.

$\begin{array}{ll}\text { BIOMEDICAL } & \text { Assets of Publishing with us } \\ \text { RESEARCHES } & \text { - Global archiving of articles } \\ & \text { - Immediate, unrestricted online access } \\ & \text { - Rigorous Peer Review Process } \\ \end{array}$

